\title{
Penalaran Berbasis Kasus Untuk Menentukan Pajak Bumi Dan Bangunan
}

\author{
Abdul Rozaq ${ }^{1}$, Latjuba Sofyana ${ }^{2}$ \\ Universitas PGRI Madiun \\ Jl. Auri No. 14-16 Madiun, (0351)496128 \\ zarozaq@gmail.com, latjubastt@unipma.ac.id
}

\begin{abstract}
Calculating land and building taxes requires a measure of land area and estimated costs when building a house. As such, tools are needed that can predict building material requirements appropriately and quickly. The CBR approach can be used to solve these problems, where the method is able to reason to solve problems based on existing cases as a solution to new problems. The system built in this study is a CBR system to determine the building material needs of a house. The consultation process is carried out by entering a new problem compared to the old case then the similarity value is calculated using the nearest neighbor. calculation with data on land area of 100 meter $^{2}$, building area of 38 meter $^{2}$, quality of type 2 building, 2 bedrooms, 1 bathroom, lightweight steel roof truss and cast tile, then the accuracy value is 0.985 of type 38 from base case so that there is an earth tax and buildings amounting to Rp. 100,389.4. The test results of 111 data test cases, obtained 9 cases that have similarity values below 0.8
\end{abstract}

Keywords: Lang and building taxe, case base reasoning, KNN

\begin{abstract}
Abstrak
Menghitung pajak bumi dan bangunan memerlukan ukuran luas tanah dan perkiraan biaya saat membangun rumah. Dengan demikian, diperlukan alat bantu yang dapat memperkirakan kebutuhan bahan bangunan dengan tepat dan cepat. Pendekatan CBR dapat melakukan penalaran untuk mencari solusi berdasarkan kasus-solusi masa lalu terhadap kasus baru. Sistem yang dibangun dalam penelitian ini adalah sistem CBR untuk menentukan pajak bumi dan bangunan berdasarkan kebutuhan bahan bangunan rumah setiap kelompok tipe rumah. Proses konsultasi dilakukan dengan cara memasukkan permasalahan baru kemudian dicari hasil yang sama atau nilai kedekatan dengan kasus lama dengan metode K- Nearest Neighbor. Perhitungan dengan dengan data luas tanah 100 meter $^{2}$, luas bangunan 38 meter $^{2}$, kwalitas bangunan nomor 2, 2 kamar tidur, 1 kamar mandi, rangka atap baja ringan dan genteng cor, maka nilai akurasi 0.985 dari tipe 38 dari basis kasus sehingga didapat pajak bumi dan bangunan sebesar Rp 100.389,42. Hasil uji coba sistem terhadap 200 data kasus uji, terdapat 28 kasus yang memiliki nilai similarity di bawah 0.8.
\end{abstract}

Kata kunci: Pajak bumi dan bangunan, penalaran berbasis kasus, KNN

\section{PENDAHULUAN}

Penelitian sebelumnya yang terkait dengan penelitian yang dilakukan oleh penulis. a) Penelitian dari [1] tentang Case Base Reasoning untuk Diagnosa Penyakit THT dapat membantu paramedis dengan hasil uji coba system 111 data kasus uji dengan hasil 9 data kasus yang memiliki similarity di bawah 0,8 [3]. b) Penelitian dari [2] tentang Case-Based Reasoning untuk Diagnosis Penyakit Jantung, hasil pengujian sistem mampu diagnosa penyakit jantung menggunakan metode nearest neighbor similarity 100\% dengan akurasi 86,21\%, minskowski distance similarity 100\% dengan akurasi 94,83\% [7]. c) Penelitian dari [3] tentang Case-Based Reasoning for Stroke Disease Diagnonis, hasil pengujian dengan $k$-fold cross validation 4 dengan threshold $(0,65),(0,7),(0,75),(0,8),(0,85),(0,9)$, dan 
0,95. Data uji 45 kasus setiap fold dan basis kasus 135 kasus. Hasil pengujian menunjukkan threshold similaritas 0,7 cocok diterapkan karena menghasilkan sensitivitas 86,95\% dan akurasi 81,67\% menggunakan indexing dan 84,44\% untuk CBR tanpa indexing merupakan yang terbaik daripada fold yang lain [5]. d) Penelitian dari [4] tentang Prediction of Length of Study of Student Applicants Using Case Based Reasoning, hasil penelitian menunjukkan pengujian terhadap 50 data adalah $76 \%$ sistem ini membantu pihak program studi untuk proses penyelenggaraan pendidikan [1]. e) Penelitian dari [5] tentang Case Based Reasoning to Identify Cause Conflicts in Marriage, hasil pengujian dilakukan dengan menggunakan data sebanyak 12 data yang terdiri dari 11 data kasus dan 1 data uji. Pada tahap penentuan kelompok konflik diperoleh nilai terbaik 0.882, dan Hasil perhitungan tingkat akurasi dengan menggunakan 35 data uji baru, didapatkan nilai sebesar 82.86\% [2]. f) Penelitian dari [6] tentang Case Base Reasoning untuk Menentukan Kebutuhan Bahan Bangunan rumah dengan Pengujian pertama dengan memasukkan data uji dibandingkan dengan masing-masing tipe rumah maka didapat akurasi sebesar 83,6\%. Pengujian kedua dilakukan dengan metode K-Fold Cross Validation dengan $\mathrm{K}=25$ dengan jumlah data sebanyak 200, data latih sebanyak 192 dan data uji sebanyak 8 data. Metode K-Fold Cross Validation. Sistem CBR ini dapat menghasilkan tingkat akurasi 98,28\% [4].

\section{METODOLOGI PENELITIAN}

\subsection{Penalaran Berbasis Kasus}

Penalaran berbasis kasus adalah metode untuk mencari solusi berdasarkan pada kasus masa lalu

\subsubsection{Siklus penalaran berbasis kasus}

Penalaran berbasis kasus dapat dikelompokkan menjadi empat proses yaitu:

1. Retrieve: mencari kasus masa lalu yang mirip atau sama dengan kasus baru

2. Reuse: menggunakan solusi dari kasus masa lalu untuk memecahkan kasus baru.

3. Revise: adaptasi solusi dari kasus masa lalu menjadi solusi kasus yang baru

4. Retain: solusi disimpan sebagai pengalaman yang berguna untuk pemecahan kasus di masa depan yang sebelumnya sudah divalidasi

Pada Gambar 1 merupakan siklus dalam CBR [7].

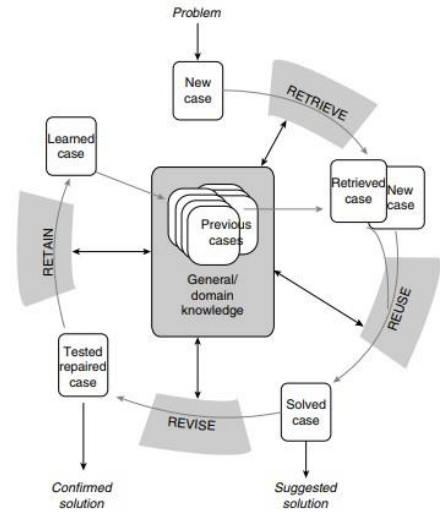

Gambar 1. Siklus Case Base Reasoning 


\subsubsection{Representasi kasus}

Informasi merupakan bagian yang penting dalam representasi kasus pada untuk memecahkan permasalahan baru dalam penalaran berbasis kasus. Kasus direpresentasikan berupa kumpulan fitur-fitur yang menjadi ciri kasus tersebut dan solusi menangani kasus tersebut. Data kumpulan kasus yang diperoleh dari tenaga ahli akan disimpan menjadi basis kasus. Pada Tabel 1 menunjukkan struktur basis kasus mempunyai atribut kode kasus, Luas Tanah, Luas Bangunan (LB), Kwalitas (KW), Jumlah Kamar Tidur (JKT), Jumlah Kamar Mandi (JKM), Jenis Rangka Atap (JKA), Jenis Atap (JA), Tabel 2 menunjukkan kebutuhan bahan bangunan sedang Tabel 3 menunjukkan representasi kasus.

Tabel 1. Struktur Basis Kasus

\begin{tabular}{|c|c|}
\hline Nama & Nilai \\
\hline Kode Kasus & К0001...K0200 \\
\hline \multicolumn{2}{|l|}{ Fitur } \\
\hline 1. Luas Tanah & $60 \ldots 150$ \\
\hline 2. Luas Bangunan & $36 \ldots 80$ \\
\hline 3. Kwalitas & KW1 ... KW5 \\
\hline 4. Jumlah Kamar Tidur & $1 \ldots 3$ \\
\hline 5. Jumlah Kamar Mandi & \\
\hline 6. Jenis Rangka Atap & $1 \ldots 2$ \\
\hline 7. Jenis Atap & $1 \ldots 5$ \\
\hline Solusi & KB001...KB200 \\
\hline
\end{tabular}

Tabel 2. Kebutuhan bahan bangunan

\begin{tabular}{|l|l|}
\hline \multicolumn{1}{|c|}{ Kolom } & \multicolumn{1}{c|}{ Nilai } \\
\hline Kode Bahan & KB001..KB200 \\
\hline Semen & $117,44 \ldots 799,93$ \\
\hline Pasir & $19,94 \ldots 80,64$ \\
\hline Batu Bata & $8904 \ldots 30560$ \\
\hline Kapur & $8,9 \ldots 118,21$ \\
\hline Kerikil & $1,88 \ldots 10,04$ \\
\hline Besi & $72 \ldots 205$ \\
\hline Begel & $57 \ldots 170$ \\
\hline K_Balok & $10 \ldots 21$ \\
\hline K_Usuk & $32 \ldots 48$ \\
\hline K_reng & $150 \ldots 320$ \\
\hline BR_Usuk & $26 \ldots 47$ \\
\hline BR_Reng & $31 \ldots 68$ \\
\hline Genteng Cor & $571 \ldots 1155$ \\
\hline Genteng Merah & $1428 \ldots 2887$ \\
\hline Metal & $92 \ldots 185$ \\
\hline
\end{tabular}




\begin{tabular}{|l|l|}
\hline \multicolumn{1}{|c|}{ Kolom } & \multicolumn{1}{c|}{ Nilai } \\
\hline Galvalum & $24 \ldots 49$ \\
\hline Asbes & $24 \ldots 49$ \\
\hline Keramik & $36 \ldots 80$ \\
\hline
\end{tabular}

Tabel 3. Contoh representasi kasus

\begin{tabular}{|c|c|c|c|}
\hline \multirow{2}{*}{ Fitur } & \multicolumn{2}{|c|}{ Permasalahan } & \multirow{2}{*}{$\begin{array}{c}\text { Permasalahan } \\
\text { Baru }\end{array}$} \\
\hline & 1 & 2 & \\
\hline Luas tanah & 150 & 100 & 100 \\
\hline Luas bangunan & 70 & 36 & 36 \\
\hline $\begin{array}{l}\text { Kwalitas } \\
\text { bangunan }\end{array}$ & KW 1 & KW 5 & KW 3 \\
\hline Kamar tidur & 3 & 2 & 2 \\
\hline Kamar mandi & 2 & 1 & 2 \\
\hline Rangka atap & Kayu & Baja ringan & Baja ringan \\
\hline Atap & Asbes & Genteng cor & Metal \\
\hline Solusi & $\begin{array}{l}\text { KB155 } \\
\text { Semen: } \\
799,93 \\
\text { Pasir: } \\
74,46 \\
\text { Bata } \\
\text { merah } \\
: 30560 \\
\text { Kapur: } \\
21,76 \\
\text { Kerikil: } \\
\text { 10,04 } \\
\text { Besi: } 205 \\
\text { Begel: } \\
\text { 170 } \\
\text { Kayu } \\
\text { balok: } 21 \\
\text { Kayu } \\
\text { usuk: } 48 \\
\text { Kayu } \\
\text { reng: } 320 \\
\text { Asbes: } 49\end{array}$ & $\begin{array}{l}\text { KB046 } \\
\text { Semen: } \\
\text { 111,44 } \\
\text { Pasir: 21,84 } \\
\text { Bata merah } \\
\text { :8904 } \\
\text { Kapur: 38,29 } \\
\text { Kerikil: 3,35 } \\
\text { Besi: 72 } \\
\text { Begel: } 60 \\
\text { Br_balok: } 26 \\
\text { Br_usuk: } 31 \\
\text { Genteng cor: } \\
\text { 571 }\end{array}$ & $?$ \\
\hline
\end{tabular}

\subsubsection{Penentuan Bobot dan Kategori}

Setiap fitur memiliki bobot penentuan kebutuhan bahan bangunan untuk membangun rumah. Fitur fitur tersebut antara lain:

a) Luas tanah

Bobot untuk fitur luas tanah diberikan nilai 1 
b) Luas bangunan

Bobot untuk fitur luas bangunan diberikan nilai 1

c) Kualitas bangunan

Fitur kualitas bangunan dikelompokkan menjadi 5 kelas:

1)KW1: mempunyai nilai 5

2)KW2: mempunyai nilai 4

3)KW3: mempunyai nilai 3

4)KW4: mempunyai nilai 2

5)KW5: mempunyai nilai 1

Bobot untuk fitur kualitas bangunan diberikan nilai 0,8

d) Jumlah kamar tidur

Bobot untuk fitur kamar tidur diberikan nilai 0,8

e) Jumlah kamar mandi

Bobot untuk fitur kamar mandi diberikan nilai 0,7

f) Jenis rangka atap

Fitur rangka atap dikelompokkan menjadi 2 kelas:

1) Baja ringan: diberikan nilai 2

2) Kayu: diberikan nilai 1

Untuk bobot fitur rangka atap diberikan nilai 0,5

g) Jenis atap

Fitur atap dibagi menjadi 5 kelas:

1) Asbes: mempunyai nilai 1

2) Galvalum: mempunyai nilai 2

3) Metal: mempunyai nilai 3

4) Genteng merah (bahan genteng terbuat dari tanah liat): mempunyai nilai 4

5) Genteng cor: mempunyai nilai 5

Untuk bobot untuk fitur atap diberikan nilai 0,5

\subsubsection{Pengukuran similarity}

Pengukuran similaritas menghasilkan nilai yang menentukan kedekatan antara kasus baru terhadap kasus yang ada dalam basis kasus. Penghitungan nilai similaritas meliputi 2 hal yaitu:

1. Similarity local

Nilai similaritas lokal untuk menghitung nilai setiap fitur.

$$
f\left(T_{i}, S_{i}\right)=1-\frac{\left\|T_{i}-S_{i}\right\|}{f_{\max }-f_{\min }}
$$

\section{Similarity global}

Digunakan untuk menghitung keserupaan antara kasus baru dengan kasus lama.

$$
\operatorname{Sim}(T, S)=\frac{\sum_{i=1}^{M} f\left(T_{i} S_{i}\right) * W_{i}}{\sum_{i=1}^{n} W_{i}}
$$




\subsection{Definisi Pajak}

Pajak merupakan iuran yang harus dibayarkan warga negara ke negara berdasarakan undang-undang dengan tidak mendapatkan jasa timbal balik secara langsung dan digunakan membayar pengeluaran kepentingan umum. Bumi merupakan tanah dan perairan serta segala sesuatu yang ada didalamnya. Bangunan merupakan bentuk dari konstruksi yang terdapat di tanah dan perairan. Karena itu gedung-gedung, jalan raya, jembatan, pabrik yang dilekatkan secara tetap dan utuh pada tanah dan perairan menjadi objek Pajak Bumi dan Bangunan.

\subsection{Perhitungan Pajak Bumi dan Bangunan}

\subsubsection{Pajak Bumi}

Perhitungan nilai jual objek pajak bumi berdasarkan luas tanah rumah dikalikan dengan harga tanah rumah saat itu

NJOP Bumi $=$ Luas Tanah $*$ Harga

\subsubsection{Pajak Bangunan}

Perhitungan nilai jual objek pajak bangunan berdasarkan luas bangunan dari rumah dikalikan dengan biaya permeter yang dibutuhkan untuk membangun rumah, untuk nilai jual objek pajak bangunan sudah dilakukan oleh sistem

NJOP Bangunan = Luas Bangunan $*$ Harga bangunan permeter

$P B B=0.5 \% * 20 \% *($ (NjOP Bumi + NJOP Bangunan $)-$ NJOTKP $)$

Perhitungan pajak bumi dan bangunan adalah total dari rumus 4 dikalikan rumus 5 dikurangkan dengan nilai jual objek tidak kena pajak sebesar 12 juta dikalikan dengan $0,5 \%$ dan $20 \%$

\section{HASIL DAN PEMBAHASAN}

\subsection{Proses Pengisian Berbasis Kasus}

Tahap awal dalam pengujian system penalaran berbasis kasus untuk penentuan pajak bumi dan bangunan ini dengan memasukkan data-data ke dalam basis kasus untuk dijadikan sebagai acuan kasus baru nantinya. Kriteria yang digunakan adalah luas tanah, luas bangunan, kwalitas bangunan, jumlah kamar tidur, jumlah kamar mandi, jenis rangka atap dan jenis atap. Selain itu untuk data basis kasus juga akan mempunyai solusi atau keputusan berupa informasi bahan bangunan sesuai dengan kriteria yang diinginkan atau mirip dengan kriteria tersebut.

\subsection{Proses Keputusan Berbasis Kasus}

Memasukkan fitur-fitur yang diinginkan ke sistem untuk diproses. Setelah data kasus baru diinputkan maka akan dipresentasikan seperti Tabel 2, selanjutnya dilakukan proses keputusan, maka sistem secara otomatis akan melakukan rangkaian proses retrieval dengan menghitung nilai similaritas setiap 
fitur yang ada di basis kasus dengan fitur kasus baru. Selanjutnya menghitung similaritas global antar setiap kasus yang ada di basis kasus dengan kasus baru. Setelah proses perhitungan similaritas selesai, kasus baru akan menggunakan kembali (reuse) solusi atau keputusan dari kasus lama yang paling mirip atau mempunyai nilai similaritas paling tinggi. Nilai similaritas berada direntang 0 sampai 1.

Tabel 4. Contoh representasi kasus data uji

\begin{tabular}{|l|c|c|}
\hline \multicolumn{1}{|c|}{ Fitur } & Kategori fitur & Permasalahan \\
\hline Luas tanah & & 100 \\
\hline Luas bangunan & - & 38 \\
\hline Kwalitas bangunan & KW2 & 4 \\
\hline Jumlah kamar tidur & - & 2 \\
\hline $\begin{array}{l}\text { Jumlah kamar } \\
\text { mandi }\end{array}$ & - & 1 \\
\hline Jenis rangka atap & Baja ringan & 2 \\
\hline Jenis atap & Genteng cor & 5 \\
\hline
\end{tabular}

Berdasarkan contoh data pada Tabel 4, perhitungan dengan menggunakan persamaan (1) dan persamaan (2) didapat similaritas tertinggi antara kasus baru dengan kasus lama adalah K00016 dengan nilai akurasi 0.985, hasil tersebut sesuai dengan tipe bangunan rumah dengan tipe 38 dan perhitungan pajak bumi dan bangunan dengan menggunakan persamaan (3), persamaan (4) dan persamaan (5) maka pajak yang harus dibayarkan sebesar Rp 100.389,42.

\subsection{Analisis Kemampuan Sistem}

Proses menganalisa kemampuan sistem penentuan pajak bumi dan bangunan bertujuan untuk mengetahui kemampuan sistem dalam penentuan keputusan. Hasil analisa sistem dengan menggunakan data pada Tabel 4 sebagai data input dengan basis kasus sebesar 200 data maka sistem menghasilkan keputusan 0,985 dari tipe 38, jika bobot dari setiap fitur yaitu luas tanah dengan bobot sebesar 1, luas bangunan dengan bobot sebesar 1, kwalitas bangunan dengan bobot sebesar 0,8, jumlah kamar tidur dengan bobot sebesar 0,7, jumlah kamar mandi dengan bobot sebesar 0.5 , jenis rangka atap dengan bobot sebesar 0,5 dan jenis atap dengan bobot sebesar 0.5 serta pajak bumi dan bangunan yang harus dibayarkan sebesar Rp 100.389,42. Walaupun pajak bumi dan bangunan sudah diatur didalam undang-undang tetapi sistem CBR bekerja apabila user memasukkan data yang tidak ada di dalam basis kasus, misal user memasukkan data rumah dengan luas bangunan 38, jumlah kamar tidur 3 maka untuk menghitung pajaka bumi dan bangunan tentu akan berbeda dengan data luas bangunan 38, jumlah kamar tidur 2 dikarenakan untuk menghitung pajak bumi dan bangunan salah satu komponen yang harus dihitung adalah biaya bangunan tentunya jumlah kamar 3 dengan jumlah kamar 2 tentunya akan berbeda. Maka sistem CBR bekerja untuk mencari solusi yang mendekati nilai tersebut, kemudian solusi tersebut akan di simpan untuk dilakukan revise bahkan retain dari pakar. 
Hasil sistem terhadap 200 data kasus uji, terdapat 28 data yang mempunyai nilai similarity di bawah 0.8 sedang tingkat akurasi $86 \%$ sesuai dengan kelompok tipe rumah yang telah dimasukkan oleh user berdasarkan luas bangunan.

Kemungkinan user memasukkan kriteria yang tidak ada di dalam basis kasus, dengan pendekatan CBR mampu melakukan penalaran serta mampu menghasilkan solusi baru yang paling mendekati dengan kasus. Setelah menghasilkan solusi baru maka solusi tersebut akan disimpan di sistem untuk dilakukan revise oleh pakar kemudian akan di retain di sistem. Dengan bertambahnya solusi baru maka sistem akan semakin baik.

\section{SIMPULAN}

Data kasus dengan luas tanah 100 meter $^{2}$, luas bangunan 38 meter $^{2}$, kwalitas bangunan nomor 2, 2 kamar tidur, 1 kamar mandi, rangka atap baja ringan dan genteng cor, maka nilai akurasi 0.985 dari tipe 38 dari basis kasus sehingga didapat pajak bumi dan bangunan sebesar Rp 100.389,42. Hasil uji coba sistem terhadap 200 data kasus uji, terdapat 28 kasus yang memiliki nilai similarity di bawah 0.8. Dalam penalaran berbasis kasus penentuan pajak bumi dan bangunan diperlukan basis kasus tipe rumah serta spesifikasi bahan bangunan yang bervariasi sehingga akan menghasilkan nilai 1 atau mendekati 1 . Apabila data yang dimasukkan oleh user tidak ada dalam basis kasus maka sistem akan mencari nilai atau solusi yang paling mendekati dengan kasus baru dengan hasil yang mendekati bisa dijadikan acuan oleh user.

Semakin banyak atau lengkap data dalam basis kasus maka sistem akan menghasil nilai 1 atau mendekati 1 sehingga semakin banyak data yang ada didalam basis kasus maka solusi yang dihasilkan akan semakin baik.

\section{DAFTAR PUSTAKA}

[1] T. Rismawan and S. Hartati, "Case-Based Reasoning untuk Diagnosa Penyakit THT (Telinga Hidung dan Tenggorokan)," IJCCS, vol. 6, no. 2, pp. 67-78, 2012.

[2] E. Wahyudi and S. Hartati, "Case-Based Reasoning untuk Diagnosis Penyakit Jantung," IJCCS (Indonesian J. Comput. Cybern. Syst., vol. 11, no. 1, p. 1, Feb. 2017.

[3] N. Rumui, A. Harjoko, and A. Musdholifah, "Case-Based Reasoning for Stroke Disease Diagnosis," IJCCS (Indonesian J. Comput. Cybern. Syst., vol. 12, no. 1, p. 33, Feb. 2018.

[4] U. S. Aesyi and R. Wardoyo, "Prediction of Length of Study of Student Applicants Using Case Based Reasoning," IJCCS (Indonesian J. Comput. Cybern. Syst., vol. 13, no. 1, p. 11, Feb. 2019.

[5] A. Ichwani and S. Suprapto, "Cased Based Reasoning to Identify Cause Conflicts in Marriage," IJCCS (Indonesian J. Comput. Cybern. Syst., vol. 13, no. 1, p. 1, Feb. 2019.

[6] A. Rozaq, "Case Base Reasoning Untuk Menentukan Kebutuhan Bahan Bangunan Rumah," SINTECH (Science Inf. Technol. J., vol. 1, no. 2, pp. 70-75, 2018.

[7] S. Shiu and S. K. Pal, Foundations of Soft Case-Based Reasoning (Wiley Series on Intelligent Systems). . 